\title{
Serum markers of fibrosis, cardiovascular and all-cause mortality in hemodialysis patients: the AURORA trial
}

\author{
Madonna Salib ${ }^{1}$ (D) Sophie Girerd ${ }^{1,2} \cdot$ Nicolas Girerd $^{1} \cdot$ Winfried März ${ }^{3,4} \cdot$ Hubert Scharnagl $^{4} \cdot$ Ziad A. Massy $^{5}$. \\ Céline Leroy ${ }^{1} \cdot$ Kévin Duarte $^{1} \cdot$ Hallvard Holdaas $^{6} \cdot$ Alan G. Jardine $^{7} \cdot$ Roland E. Schmieder $^{8} \cdot$ Bengt Fellström $^{9}$. \\ Natalia López-Andrés ${ }^{10} \cdot$ Patrick Rossignol $^{1} \cdot$ Faiez Zannad $^{1}$
}

Received: 15 March 2021 / Accepted: 14 June 2021 / Published online: 25 June 2021

(c) The Author(s) 2021

\begin{abstract}
Background Biomarkers of fibrosis are associated with outcome in several cardiovascular diseases. However, their relevance to chronic kidney disease and dialysis is uncertain, as it remains unclear how the kidneys and the dialysis procedure itself affect their elimination and degradation. We aimed to investigate the relationship of the blood levels of two markers associated with fibrosis: procollagen type I C-terminal pro-peptide (PICP) and galectin-3 (Gal-3) with mortality in dialysis patients.

Methods Procollagen type I C-terminal pro-peptide and galectin-3 were measured at baseline in 2773 patients enrolled in the AURORA trial, investigating the effect of rosuvastatin on cardiovascular outcomes, in patients on hemodialysis, and their interaction with $\mathrm{CV}$ death or all-cause mortality using survival models. The added prognostic value of these biomarkers was assessed by the net reclassification improvement (NRI).

Results The median follow-up period was 3.8 years. Blood concentrations of PICP and Gal-3 were significantly associated with $\mathrm{CV}$ death [adjusted HR per $1 \mathrm{SD}=1.11(1.02-1.20)$ and $\mathrm{SD}=1.20(1.10-1.31)$, respectively] and all-cause mortality (all adjusted $p<0.001$ ). PICP and Gal-3 had a synergistic effect with regard to CV death and all-cause mortality (interaction $p=0.04$ and 0.01 , respectively). Adding PICP, Gal-3 and their interaction on top of clinical and biological covariates, resulted in significantly improved prognostic accuracy NRI $=0.080(0.019-0.143)$ for CV death.

Conclusion In dialysis patients, concomitant increase in PICP and Gal-3 concentrations are associated with higher rates of $\mathrm{CV}$ death. These results suggest that concomitantly raised PICP and Gal-3 may reflect an activated fibrogenesis relevant to risk stratification in dialysis, raising the hypothesis that anti-fibrotic therapy may be beneficial for cardiovascular protection in such patients.
\end{abstract}

Faiez Zannad

f.zannad@chru-nancy.fr

1 Université de Lorraine, Inserm, Centre d'Investigations Cliniques-1433, and Inserm U1116, CHRU Nancy; F-CRIN INI-CRCT, Nancy, France

2 Nephrology Department, University Hospital of Nancy, Vandoeuvre les Nancy, Nancy, France

3 Medical Clinic V (Nephrology, Hypertensiology, Rheumatology, Endocrinology, Diabetology), Medical Faculty Mannheim, University of Heidelberg, Theodor-Kutzer-Ufer 1-3, 68167 Mannheim, Germany

4 Clinical Institute of Medical and Chemical Laboratory Diagnostics, Medical University of Graz, 8036 Graz, Austria

5 Division of Nephrology, Ambroise Paré University Hospital, APHP, Boulogne Billancourt/Paris, and INSERM U-1018, Centre de recherche en épidémiologie et santé des populations (CESP), Equipe 5, Paris-Saclay University (PSU) and University of Paris Ouest-Versailles-Saint-Quent in-en-Yvelines (UVSQ), FCRIN INI-CRCT, Villejuif, France
6 Medical Department, Rikshospitalet, University of Oslo, Oslo, Norway

7 Renal Research Group, British Heart Foundation Cardiovascular Research Centre, Institute of Cardiovascular and Medical Sciences, University of Glasgow, Glasgow, UK

8 Department of Nephrology and Hypertension, University Hospital Erlangen, Erlangen, Germany

9 Department of Nephrology, University Hospital, Uppsala, Sweden

10 Navarrabiomed, Complejo Hospitalario de Navarra (CHN), Universidad Pública de Navarra (UPNA), IdiSNA, Pamplona, Spain 


\section{Graphic abstract}

Serum markers of fibrosis, cardiovascular and all-cause mortality in

hemodialysis patients: the AURORA trial

\begin{tabular}{|c|c|c|c|c|}
\hline STUDY DESIGN & \multicolumn{4}{|c|}{ RESULTS } \\
\hline \multirow{2}{*}{$\begin{array}{l}2773 \text { hemodialysis patients from the AURORA } \\
\text { trial (RCT evaluating the effect of rosuvastatin) in } \\
\text { whom we quantified the serum levels of } \\
\quad \text { Procollagen type I C-terminal pro-peptide } \\
\text { (PICP) } \\
\quad \text { Galectin-3 (Gal-3) }\end{array}$} & $\begin{array}{c}\text { Association of } \\
\text { biomarkers with CV } \\
\text { death (HR per 1 SD) }\end{array}$ & \begin{tabular}{|c|} 
PICP \\
HR $=1.11$ \\
$(1.02-1.20)$
\end{tabular} & $\begin{array}{c}\text { Gal-3 } \\
\mathrm{HR}=1.20 \\
(1.10-1.31)\end{array}$ & $\begin{array}{c}\text { hs-CRP } \\
\mathrm{HR}=1.17 \\
(1.10-1.26)\end{array}$ \\
\hline & \multicolumn{2}{|c|}{ Interaction of PICP and Gal-3 } & \multirow{2}{*}{\multicolumn{2}{|c|}{$\begin{array}{l}\text { Added prognostic value } \\
\text { of PICP and Gal-3 on top } \\
\text { of clinical and biological }\end{array}$}} \\
\hline OBJECTIVE & \multirow{2}{*}{ (1) } & & & \\
\hline $\begin{array}{l}\text { Investigate the prognostic value of } \\
\text { PICP and Gal-3 for CV outcomes }\end{array}$ & & & \multicolumn{2}{|c|}{$\begin{array}{l}\mathrm{NRI}=0.080 \\
(0.019 \text { to } 0.143) \\
\text { for } \mathrm{CV} \text { death }\end{array}$} \\
\hline
\end{tabular}

Keywords Hemodialysis · Collagen · Fibrosis · Biomarker · Galectin-3 · Cardiovascular diseases

\section{Introduction}

Cardiovascular (CV) diseases are the leading cause of mortality in patients on dialysis. But for now, no therapeutic intervention was proven to improve CV outcomes [1,2].

Several studies reported that patients with end-stage renal disease (ESRD) and undergoing hemodialysis (HD) have increased level of inflammation and oxidative stress, which are associated with a higher risk of CV death [3-6]. These mechanisms can lead to high collagen turnover resulting in fibrosis [7], which could be a therapeutic target.

In heart failure (HF), circulating biomarkers of myocardial fibrosis, in particular collagen turnover biomarkers, may be useful for predicting clinical risk or response to treatment $[8,9]$. Collagen I and III are also identified as relevant biomarkers of vascular disease in chronic kidney disease (CKD), as they were associated with arterial stiffness [10, 11]. Nevertheless, in non-dialysis CKD patients, the interpretation of collagen biomarkers may be difficult as they may reflect the process of renal fibrosis, the decrease of the glomerular filtration rate (for biomarkers of low molecular weight), increased bone collagen turnover, as well as fibrosis in non-renal and non-cardiovascular tissue (i.e., liver or lungs) [12].

Serum procollagen type I C-terminal pro-peptide (PICP) was found to be correlated with total myocardial collagen volume fraction in patients with hypertensive heart disease. This would suggest that PICP is a key marker of the development of myocardial fibrosis [13, 14].

Galectin-3 (Gal-3) is a marker of inflammation and is involved in aldosterone-mediated fibrosis [15, 16]. According to guidelines [17], Gal-3 can be used for additional risk stratification in HF. Gal-3 acts as a profibrotic agent within the kidneys and therefore high plasma concentrations precede the development of CKD $[15,16]$. Considering the negative association between Gal-3 and renal functions, its prognostic utility for $\mathrm{CV}$ disease in non-dialyzed CKD is controversial [18], but in dialysis, several studies reported an association between the concentration of Gal-3 and CV mortality [19-22].

In this framework, the investigation of PICP, a circulating collagen synthesis biomarker, in combination with Gal-3 could be a future strategy to identify patients at particularly high CV risk in hemodialysis, because these biomarkers may reflect active cardiovascular fibrogenesis.

We primarily aimed to evaluate the association of PICP and Gal-3 with adjudicated CV outcomes in the large multicenter, randomized control AURORA trial (a study to evaluate the use of rosuvastatin in subjects on regular hemodialysis: an assessment of survival and cardiovascular events). In addition, as PICP and Gal-3 could complementarily investigate ongoing active fibrosis, we investigated their interplay with regard to clinical outcomes, and further attempted to identify a fibrotic biomarker phenotype [23].

\section{Methods}

\section{Study population}

The description, baseline data and main results of the AURORA study have been published previously [24-26]. In short, AURORA is a double-blind, randomized, multicenter study involving 2773 men and women aged $50-80$ years, 
who had been treated with maintenance hemodialysis or hemofiltration for at least 3 months. After providing written informed consent, eligible patients were randomly assigned in a $1: 1$ ratio to receive either rosuvastatin, $10 \mathrm{mg}$ daily or matching placebo.

There was no significant effect of rosuvastatin on the composite primary endpoint of major adverse cardiovascular event (MACE) (i.e., nonfatal myocardial infarction, nonfatal stroke, or death from CV causes) [HR 0.96 (95\% CI $0.84-1.11), p=0.59)$. Rosuvastatin also exhibited no significant effects on the secondary endpoint of all-cause mortality [HR 0.96 (95\% CI 0.86-1.07), $p=0.51$ ].

\section{Outcomes}

The pre-specified considered outcomes are CV death, allcause mortality, and the composite primary endpoint of the AURORA trial (MACE). All the recorded events were reviewed and adjudicated by a clinical endpoint committee to ensure consistency of the event diagnosis. The committee members were unaware of the randomized treatment assignments.

\section{Biomarkers}

PICP [reference range, $69-163 \mathrm{ng} / \mathrm{mL}$ ] was measured in serum samples by an ELISA (Quidel Corporation, Santa Clara, USA). The dynamic range for this assay is $0.2-80 \mathrm{ng} /$ $\mathrm{mL}$ and interassay coefficients of variation were $7 \%$.

Gal-3 was measured in serum by a chemiluminescent microparticle immunoassay (CMIA, Abbott GmbH, Wiesbaden, Germany) on an Abbott ARCHITECT i2000 analyzer. Interassay coefficients of variation were 4.4, 5.2, and $1.6 \%$ at low, middle and high concentrations.

PICP was available for all the 2349 patients of the AURORA trial and Gal-3 as available for 2343 patients of the study.

\section{Statistical analysis}

Categorical variables are expressed as frequencies (\%) and continuous variables are expressed as means \pm standard deviation or median (25th and 75th percentiles), depending on the variable distribution.

Associations of PICP and Gal-3 with CV death, allcause mortality or MACE were assessed using both continuous and categorized variables (tertiles) using Cox models. Models were adjusted on clinical and biological covariates based on previously published data in AURORA [23] (age, history of CV disease, diabetes mellitus, albumin, and high sensitivity C-reactive protein), and variables correlated to PICP and Gal-3 concentrations (sex, dialysis vintage, body mass index, systolic blood pressure). History of CV disease is defined by history of coronary heart disease (i.e., prior myocardial infarction, prior coronary angioplasty or stent, and coronary artery bypass graft), history of vascular disease (i.e., peripheral artery disease, abdominal aortic aneurysm, carotid artery disease, carotid stenosis $\geq 50 \%$, and carotid endarterectomy), and history of neurovascular disease (i.e., prior ischemic vascular accident and transient ischemic attack). High sensitivity C-reactive protein (hs-CRP) was best modeled by using its natural logarithm. Interaction between PICP and Gal-3 was assessed using a multiplicative interaction term in the Cox models.

The added prognostic value of PICP and Gal-3 in predicting $\mathrm{CV}$ death or all-cause mortality was assessed by the net reclassification improvement (NRI) on top of routine prognostic variables used as adjustment variables (i.e., age, history of CV disease, diabetes mellitus, sex, dialysis vintage, body mass index, systolic blood pressure, albumin and log hs-CRP at baseline).

All analyses were performed using $\mathrm{R}$ version 3.6.1 ( $\mathrm{R}$ Development Core Team, Vienna, Austria). The two-sided significance level was set at $p$ value $<0.05$.

\section{Results}

\section{Baseline characteristics of patients across the tertiles of each biomarker}

The mean PICP was $176 \pm 91 \mathrm{ng} / \mathrm{mL}$ and mean Gal-3 concentration was $69 \pm 25 \mathrm{ng} / \mathrm{mL}$. The correlation between PICP and Gal-3 was weak (Pearson correlation 0.068, $p=0.002)$. The correlation between hs-CRP and Gal-3 was also weak (Pearson correlation 0.124, $p<0.0001$ ), whereas there was no correlation between hs-CRP and PICP (Pearson correlation $-0.009, p=0.64$ ).

Patients with higher PICP concentrations were younger (median age 63 in tertile (T) 3 vs. 66 in $T 1, p<0.001$ ) and had longer dialysis vintage (median 3.88 years vs. 2.04, $p<0.001$ ). Concentrations of hs-CRP were similar across the PICP tertiles. Patients with higher PICP concentrations were more likely to be women $(p<0.001)$ and had lower BMI $(p<0.001)$, and lower hemoglobin levels $(p<0.001)$ (Table 1).

Patients with higher Gal-3 concentrations were younger (median age 63 in $T 3$ vs. 65 in $T 1, p=0.008$ ), had longer dialysis vintage (median 3.82 years vs. $1.89, p<0.001$ ) and higher levels of hs-CRP $(p<0.001)$ (Table 2).

The hs-CRP (mg/L) tertiles are presented in Supplementary Table 1. 
Table 1 Baseline characteristics according to PICP tertiles

\begin{tabular}{|c|c|c|c|c|}
\hline $\begin{array}{l}\text { PICP } \\
\text { (ng/mL) }\end{array}$ & $\begin{array}{l}\text { 1st tertile } \\
(11.3-130)\end{array}$ & $\begin{array}{l}\text { 2nd tertile } \\
(>130-186)\end{array}$ & $\begin{array}{l}\text { 3rd tertile } \\
(>186-800)\end{array}$ & $p$ value \\
\hline$n$ & 783 & 784 & 782 & \\
\hline Female gender (\%) & $271(34.6)$ & $284(36.2)$ & $343(43.9)$ & $<0.001$ \\
\hline Age (years) & 66 [58-73] & $66[57-73]$ & $63[56-71]$ & $<0.001$ \\
\hline Dialysis vintage (years) & $2.04[0.91-4.35]$ & $2.53[1.05-4.86]$ & $3.88[1.77-7.69]$ & $<0.001$ \\
\hline Measured $\left(\mathrm{K}_{\mathrm{t}} / \mathrm{V}\right)$ & $1.36[1.19-1.58]$ & $1.36[1.20-1.56]$ & $1.36[1.19-1.59]$ & 0.915 \\
\hline Albumin $(\mathrm{g} / \mathrm{L})$ & $39.73(3.35)$ & $39.71(3.47)$ & $39.37(3.53)$ & 0.065 \\
\hline Hemoglobin (g/dL) & $11.89(1.51)$ & $11.78(1.53)$ & $11.45(1.65)$ & $<0.001$ \\
\hline hs-CRP (mg/L) & $1.01(1.14)$ & $1.02(1.17)$ & $1.01(1.18)$ & 0.984 \\
\hline BMI $\left(\mathrm{kg} / \mathrm{m}^{2}\right)$ & $25.53(4.90)$ & $25.73(5.05)$ & $24.71(4.73)$ & $<0.001$ \\
\hline Systolic blood pressure (mmHg) & $134(23.15)$ & $135(24.01)$ & $138(25.46)$ & 0.003 \\
\hline Diastolic blood pressure (mmHg) & $74(12.35)$ & $75(12.11)$ & $77(13.01)$ & $<0.001$ \\
\hline Pulse pressure $(\mathrm{mmHg})$ & 60 [49-70] & $60[46-71]$ & $60[50-73]$ & 0.368 \\
\hline Current smoker (\%) & $139(17.8)$ & $123(15.7)$ & $116(14.8)$ & 0.271 \\
\hline Diabetes $(\%)$ & $199(25.4)$ & $200(25.5)$ & $190(24.3)$ & 0.827 \\
\hline Peripheral artery disease (\%) & $136(17.4)$ & $111(14.2)$ & $116(14.8)$ & 0.179 \\
\hline History of coronary heart disease $(\%)$ & $106(13.5)$ & $106(13.5)$ & $100(12.8)$ & 0.883 \\
\hline History of cardiovascular disease (\%) & $284(36.3)$ & $270(34.4)$ & $237(30.3)$ & $\mathbf{0 . 0 3 8}$ \\
\hline Cause of ESRD, $n(\%)$ & & & & 0.088 \\
\hline Diabetes & $136(17.4)$ & $146(18.6)$ & $133(17.0)$ & \\
\hline Genetic conditions & $100(12.8)$ & $106(13.5)$ & $104(13.3)$ & \\
\hline Glomerulonephritis or vasculitis & $126(16.1)$ & $160(20.4)$ & $173(22.1)$ & \\
\hline Nephropathy or nephrosclerosis & $180(23.0)$ & $145(18.5)$ & $134(17.1)$ & \\
\hline Pyelonephritis or interstitial & $119(15.2)$ & 109 (13.9) & $128(16.4)$ & \\
\hline Unknown/unspecified & $80(10.2)$ & $75(9.6)$ & $76(9.7)$ & \\
\hline Other & $42(5.4)$ & $43(5.5)$ & $34(4.3)$ & \\
\hline
\end{tabular}

$h s$-CRP high sensitivity C-reactive protein, $B M I$ body mass index, ESRD end-stage renal disease

Results with $p$ value less than $5 \%$ were emphasized using bold letters

\section{Association of PICP, Gal-3, and hs-CRP with CV mortality, all-cause mortality, and MACE}

In multivariable analysis (Table 3), after adjusting for key prognostic factors (including age which was inversely correlated to PICP concentrations), PICP was associated with $\mathrm{CV}$ death [HR per $1 \mathrm{SD}=1.11(1.02-1.20)]$. PICP was also significantly associated with all-cause mortality [HR per $1 \mathrm{SD}=1.12(1.05-1.19)$ and HR for $T 3$ vs. $T 1=1.26$ (1.08-1.46)] (Table 3).

The association of Gal-3 either considered as a continuous variable or categorized variable with $\mathrm{CV}$ death and all-cause mortality were significant in multivariable models [adjusted HR per $1 \mathrm{SD}=1.20(1.10-1.31)$ and 1.18 (1.10-1.25), respectively; adjusted HR for $T 3$ vs. $T 1=1.36$ (1.11-1.67) and 1.26 (1.08-1.46), respectively] (Table 3).

Gal-3 as a continuous variable was significantly associated with MACE [crude HR per $1 \mathrm{SD}=1.11(1.03-1.19)$ and adjusted HR per $1 \mathrm{SD}=1.15(1.07-1.24)]$. However, PICP either considered as a continuous variable or categorized variable was not significantly associated with MACE
(Supplementary Table 2). Age, diabetes, history of CV disease, as well as a low serum albumin or an elevated hs-CRP were also significantly associated with MACE in the models (Supplementary Table 3).

When further including an interaction term between biomarkers tertiles (either PICP or Gal-3) and dialysis vintage in the multivariable models, we did not identify a significant modification of the associations of biomarkers with $\mathrm{CV}$ death, all-cause mortality and MACE related to dialysis vintage ( $p$ for interaction $>0.05$, data not shown). Also, further including the underlying cause of ESRD in the multivariable models did not significantly change the association of biomarkers (either PICP or Gal-3) as a continuous variable or categorized variable with $\mathrm{CV}$ death, all-cause mortality, and MACE (data not shown).

The effect of PICP (per 1-SD) and Gal-3 (per 1-SD) on $\mathrm{CV}$ death was homogenous across pre-specified subgroups. In contrast, the association of PICP with all-cause mortality was stronger in patients without history of $\mathrm{CV}$ disease $[p$ for interaction $=0.012$ (Fig. 1 ); $p$ for interaction in multivariable adjusted analysis $=0.010$ (Supplementary 
Table 2 Baseline characteristics according to Gal-3 tertiles

\begin{tabular}{|c|c|c|c|c|}
\hline $\begin{array}{l}\text { Gal-3 } \\
\text { (ng/mL) }\end{array}$ & $\begin{array}{l}\text { 1st tertile } \\
(11.2-56.3)\end{array}$ & $\begin{array}{l}\text { 2nd tertile } \\
(>56.3-78)\end{array}$ & $\begin{array}{l}\text { 3rd tertile } \\
(>78-228)\end{array}$ & $p$ value \\
\hline$N$ & 782 & 780 & 781 & \\
\hline Female gender $(\%)$ & $284(36.3)$ & $291(37.3)$ & $313(40.1)$ & 0.283 \\
\hline Age (years) & $65[57-73]$ & $65[57-72]$ & $63[56-71]$ & 0.008 \\
\hline Dialysis vintage (years) & $1.89[0.83-4.02]$ & $2.87[1.24-5.34]$ & $3.82[1.78-7.01]$ & $<0.001$ \\
\hline Measured $\left(\mathrm{K}_{t} / \mathrm{V}\right)$ & $1.34[1.20-1.56]$ & 1.38 [1.19-1.60] & $1.36[1.20-1.56]$ & 0.508 \\
\hline Albumin (g/L) & $39.73(3.44)$ & $39.95(3.46)$ & $39.26(3.53)$ & $<0.001$ \\
\hline Hemoglobin (g/dL) & $11.76(1.49)$ & $11.68(1.63)$ & $11.57(1.66)$ & 0.067 \\
\hline hs-CRP (mg/L) & $0.88(1.07)$ & $0.95(1.12)$ & $1.22(1.27)$ & $<0.001$ \\
\hline BMI $\left(\mathrm{kg} / \mathrm{m}^{2}\right)$ & $25.16(4.82)$ & $25.40(4.64)$ & $25.31(5.30)$ & 0.618 \\
\hline Systolic blood pressure (mmHg) & $138(21.69)$ & $138(25.01)$ & $136(26.32)$ & 0.342 \\
\hline Diastolic blood pressure (mmHg) & $76(12.12)$ & $76(12.36)$ & $76(13.51)$ & 0.867 \\
\hline Pulse pressure (mmHg) & $60[50-72]$ & $60[49-74]$ & $60[48-70]$ & 0.100 \\
\hline Current smoker (\%) & $128(16.4)$ & $117(15.0)$ & $117(15.0)$ & 0.685 \\
\hline Diabetes $(\%)$ & $220(28.1)$ & $197(25.3)$ & $187(23.9)$ & 0.153 \\
\hline Peripheral artery disease (\%) & $113(14.5)$ & $124(15.9)$ & $108(13.8)$ & 0.496 \\
\hline History of coronary heart disease (\%) & $102(13.0)$ & $103(13.2)$ & $93(11.9)$ & 0.704 \\
\hline History of cardiovascular disease (\%) & $262(33.5)$ & $256(32.8)$ & $241(30.9)$ & 0.522 \\
\hline Cause of ESRD, $n(\%)$ & & & & 0.119 \\
\hline Diabetes & $155(19.8)$ & $141(18.1)$ & $136(17.4)$ & \\
\hline Genetic conditions & $101(12.9)$ & $111(14.2)$ & $89(11.4)$ & \\
\hline Glomerulonephritis or vasculitis & $126(16.1)$ & $133(17.1)$ & $163(20.9)$ & \\
\hline Nephropathy or nephrosclerosis & 161 (20.6) & $156(20.0)$ & $151(19.3)$ & \\
\hline Pyelonephritis or interstitial & $131(16.8)$ & $115(14.7)$ & $115(14.7)$ & \\
\hline Unknown/unspecified & $67(8.6)$ & $94(12.1)$ & $91(11.7)$ & \\
\hline Other & $41(5.2)$ & $30(3.8)$ & $36(4.6)$ & \\
\hline
\end{tabular}

$B M I$ body mass index, $E S R D$ end-stage renal disease

Results with $p$ value less than 5\% were emphasized using bold letters
Fig. 1)] and without history of coronary diseases [ $p$ for interaction $=0.084$ (Fig. 1); $p$ for interaction in multivariable adjusted analysis $=0.048$ (Supplementary Fig. 1)] The association of Gal-3 with all-cause mortality was also stronger in patients without history of coronary diseases $[(p$ for interaction $=0.077$ (Fig. 2); $p$ for interaction in multivariable adjusted analysis $=0.085$ (Supplementary Fig. 2).

\section{Interaction of PICP, Gal-3 and hs-CRP to predict CV mortality, all-cause mortality, and MACE}

We identified a significant positive interaction between PICP and Gal-3 with regard to $\mathrm{CV}$ death and all-cause mortality ( $p$ for interaction with continuous variables $=0.04$ and 0.01 , respectively).

The magnitude of the association of an elevated concentration of PICP with either $\mathrm{CV}$ death or all-cause mortality was more pronounced among patients having also an elevated concentration of Gal-3 (Fig. 3). Patients with both raised PICP and Gal-3 had sizeable increase in rates for $\mathrm{CV}$ death (HR in patients in T3 of PICP and T3 of Gal-3=1.64, $p=0.004)$, whereas patients with isolated Gal-3 or PICP increase, respectively, had no significant increase in rates of CV death (all $p>0.20$, Fig. 3). In contrast, there was no significant interaction between hs-CRP and PICP regarding the association with either $\mathrm{CV}$ death or all-cause mortality (Supplementary Fig. 3).

Interaction between PICP and Gal-3 with regard to MACE tended to be significant ( $p=0.055)$, and only patients with elevated Gal-3 and PICP had significantly increased from the risk of MACE [HR = 1.36 (1.00-1.84), Supplementary Fig. 4].

There was no significant interaction between rosuvastatin therapy and PICP and Gal-3 concentration (data not shown).

\section{Added value of PICP, Gal-3 and hs-CRP to predict CV mortality and all-cause mortality}

PICP per 1 SD increase significantly improved the prediction $[\mathrm{NRI}=0.072(0.012-0.115)]$ of all-cause mortality on top of the routine clinical and biological model based on the variables used for adjustment (i.e., age, history of $\mathrm{CV}$ 
Table 3 Association of PICP, Gal-3 and hs-CRP with cardiovascular death and allcause mortality

\begin{tabular}{|c|c|c|c|c|c|c|}
\hline \multirow[t]{2}{*}{ Variables } & \multirow{2}{*}{$\begin{array}{l}\text { Univariable } \\
\text { HR }(95 \% \text { CI) }\end{array}$} & \multirow[t]{2}{*}{$p$ value } & \multicolumn{4}{|l|}{ Multivariable } \\
\hline & & & $\begin{array}{l}\text { Model } 1 \\
\text { HR }(95 \% \text { CI) }\end{array}$ & $p$ value & $\begin{array}{l}\text { Model } 2 \\
\text { HR }(95 \% \text { CI })\end{array}$ & $p$ value \\
\hline \multicolumn{7}{|c|}{ Cardiovascular death $(n=648)$} \\
\hline \multicolumn{7}{|c|}{ PICP } \\
\hline Per 1SD & $1.06(0.98-1.15)$ & 0.13 & $1.12(1.03-1.21)$ & 0.01 & $1.11(1.02-1.20)$ & 0.017 \\
\hline \multicolumn{7}{|l|}{ Tertiles } \\
\hline 1st tertile & 1 & - & 1 & - & 1 & - \\
\hline 2nd tertile & $1.00(0.82-1.23)$ & 0.98 & $1.01(0.82-1.25)$ & 0.89 & $1.01(0.82-1.24)$ & 0.96 \\
\hline 3rd tertile & $1.14(0.93-1.39)$ & 0.20 & $1.22(0.99-1.50)$ & 0.061 & $1.22(0.99-1.50)$ & 0.068 \\
\hline \multicolumn{7}{|l|}{ Gal-3 } \\
\hline Per 1SD & $1.15(1.06-1.24)$ & 0.0006 & $1.23(1.15-1.31)$ & $<0.0001$ & $1.20(1.10-1.31)$ & $<0.0001$ \\
\hline \multicolumn{7}{|l|}{ Tertiles } \\
\hline 1st tertile & 1 & - & 1 & - & 1 & - \\
\hline 2nd tertile & $1.11(0.91-1.36)$ & 0.31 & $1.16(0.94-1.42)$ & 0.16 & $1.14(0.93-1.40)$ & 0.21 \\
\hline 3rd tertile & $1.29(1.06-1.57)$ & 0.012 & $1.46(1.19-1.79)$ & 0.0003 & $1.36(1.11-1.67)$ & 0.003 \\
\hline \multicolumn{7}{|l|}{ hs-CRP ${ }^{\mathrm{a}}$} \\
\hline Log hs-CRP & $1.24(1.16-1.32)$ & $<0.0001$ & $1.22(1.15-1.30)$ & $<0.0001$ & $1.17(1.10-1.26)$ & $<0.0001$ \\
\hline \multicolumn{7}{|l|}{ Tertiles } \\
\hline 1st tertile & 1 & - & 1 & - & 1 & - \\
\hline 2nd tertile & $1.14(0.94-1.40)$ & 0.19 & $1.14(0.93-1.40)$ & 0.20 & $1.09(0.89-1.34)$ & 0.39 \\
\hline 3rd tertile & $1.66(1.38-2.01)$ & $<0.0001$ & $1.62(1.33-1.97)$ & $<0.0001$ & $1.42(1.16-1.73)$ & 0.0008 \\
\hline \multicolumn{7}{|c|}{ All-cause mortality $(n=1296)$} \\
\hline \multicolumn{7}{|l|}{ PICP } \\
\hline Per 1SD & $1.07(1.01-1.13)$ & 0.021 & $1.12(1.06-1.19)$ & 0.0002 & $1.12(1.05-1.19)$ & 0.0002 \\
\hline \multicolumn{7}{|l|}{ Tertiles } \\
\hline 1st tertile & 1 & - & 1 & - & 1 & - \\
\hline 2nd tertile & $1.09(0.94-1.26)$ & 0.24 & $1.09(0.94-1.26)$ & 0.25 & $1.09(0.94-1.26)$ & 0.28 \\
\hline 3rd tertile & $1.18(1.02-1.36)$ & 0.027 & $1.26(1.08-1.46)$ & 0.003 & $1.26(1.08-1.46)$ & 0.003 \\
\hline \multicolumn{7}{|l|}{ Gal-3 } \\
\hline Per 1SD & $1.14(1.08-1.21)$ & $<0.0001$ & $1.21(1.14-1.29)$ & $<0.0001$ & $1.18(1.10-1.25)$ & $<0.0001$ \\
\hline \multicolumn{7}{|l|}{ Tertiles } \\
\hline 1st tertile & 1 & - & 1 & - & 1 & - \\
\hline 2nd tertile & $1.05(0.91-1.22)$ & 0.50 & $1.10(0.95-1.28)$ & 0.22 & $1.08(0.93-1.26)$ & 0.30 \\
\hline 3rd tertile & $1.23(1.06-1.42)$ & 0.006 & $1.38(1.19-1.61)$ & $<0.0001$ & $1.26(1.08-1.46)$ & 0.003 \\
\hline \multicolumn{7}{|l|}{ hs-CRP ${ }^{\mathrm{a}}$} \\
\hline Log hs-CRP & $1.28(1.22-1.33)$ & $<0.0001$ & $1.28(1.22-1.34)$ & $<0.0001$ & $1.22(1.17-1.28)$ & $<0.0001$ \\
\hline \multicolumn{7}{|l|}{ Tertiles } \\
\hline 1st tertile & 1 & - & 1 & - & 1 & - \\
\hline 2nd tertile & $1.31(1.14-1.51)$ & 0.0002 & $1.34(1.16-1.56)$ & $<0.0001$ & $1.29(1.11-1.49)$ & 0.0007 \\
\hline 3rd tertile & $1.90(1.66-2.18)$ & $<0.0001$ & $1.91(1.66-2.20)$ & $<0.0001$ & $1.68(1.45-1.94)$ & $<0.0001$ \\
\hline
\end{tabular}

Model 1: adjusted for age, diabetes, history of cardiovascular disease, sex, dialysis vintage, body mass index, and systolic blood pressure (at baseline)

Model 2: model $1+$ albumin and log hs-CRP (at baseline)

${ }^{a}$ Model 2: model $1+$ albumin (at baseline)

Results with $p$ value less than $5 \%$ were emphasized using bold letters disease, diabetes mellitus, sex, dialysis vintage, body mass index, systolic blood pressure, albumin and log hs-CRP at baseline). Gal-3 significantly improved the prediction of both CV death and all-cause mortality on top of the clinical and biological model [NRI $=0.101(0.024-0.146)$ and $\mathrm{NRI}=0.080$ (0.015-0.113), respectively]. 
CV death

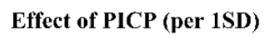

Overall efrect

Treatment

Placebo

Rovusastatin

Diabetes Mellitus

No

Yes

CVD history

$$
\text { No }
$$

Yes

CHD history

No

Yes

Age

$\leq$ median

$>$ median

Albumin

$\leq$ median

$>$ median

Yrs on RRT

$\leq$ median

$>$ median

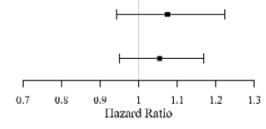

HR (CI 95\%) Interaction p-value

$1.06(0.98-1.15)$

$1.06(0.94-1.18)$

$1.07(0.96-1.20)$

$1.08(0.99-1.19)$

$1.07(0.91-1.25)$

$1.12(1.01-1.24)$

$1.02(0.90-1.15)$

$1.08(0.99-1.18)$

$0.97(0.81-1.17)$

$1.09(0.97-1.22)$

$1.10(0.98-1.22)$

$1.04(0.94-1.15)$

$1.08(0.95-1.23)$

$1.07(0.94-1.22)$

$1.05(0.95-1.17)$

0.85

0.23

$$
0.31
$$

$$
0.93
$$

0.61

0.82

All-cause mortality

HR (CI 95\%)

Interaction p-value

87

.31

0.93

85

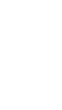

$\sqrt{2}+2$

93

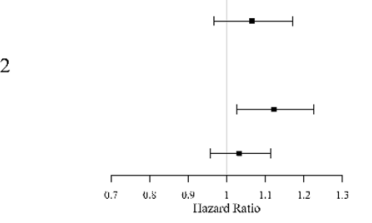

$1.07(1.01-1.13)$

0.94

$1.07(0.99-1.16)$

$1.07(0.98-1.16)$

0.30

$1.06(0.99-1.14)$

$1.14(1.02-1.27)$

0.012

$1.15(1.07-1.23)$

$0.99(0.90-1.08)$

0.084

$1.09(1.03-1.16)$

$0.95(0.83-1.10)$

0.53

$1.12(1.03-1.21)$

$1.08(1.00-1.17)$

0.93

$1.06(0.98-1.14)$

$1.06(0.97-1.17)$

$1.12(1.03-1.23)$

$1.03(0.96-1.11)$

Fig. 1 Association between PICP and cardiovascular death or all-cause mortality in subgroups of patients (non-adjusted analysis). CVD cardiovascular diseases, $C H D$ coronary heart diseases, $\operatorname{Yrs} R R T$ years on renal replacement therapy (dialysis vintage)

Adding PICP, Gal-3 and their interaction on top of the clinical and biological model (i.e., age, history of CV disease, diabetes mellitus, sex, dialysis vintage, body mass index, systolic blood pressure, albumin and log hs-CRP at baseline) resulted in significant NRI for CV death and all-cause mortality $[\mathrm{NRI}=0.080(0.019-0.143)$ and 0.085 (0.029-0.129), respectively]. Of note, this prediction improvement was of similar magnitude to the one derived from hs-CRP on top of usual clinical/biological variables (i.e., age, history of CV disease, diabetes mellitus, sex, dialysis vintage, body mass index, systolic blood pressure, and albumin but obviously excluding log hs-CRP at baseline) [NRI for CV death $=0.108(0.050-0.167)$ and NRI for allcause mortality $=0.132(0.088-0.171)$, respectively $]$.

\section{Discussion}

To the best of our knowledge, the current study is the first to assess the combined and synergistic association of PICP and Gal-3 with CV death and all-cause mortality in hemodialysis patients. Our main findings are as follows: (1) increased concentrations of PICP or Gal-3 are significantly associated with CV death and all-cause mortality even after adjusting on a previously validated clinical and biological score in the AURORA trial [23], and the correlated variables; (2) the increment of association with CV death provided by PICP and Gal-3 was of similar magnitude of the one provided by hs-CRP [HR per 1 SD $1.11(1.02-1.20)=1.20(1.10-1.31)$ and 1.17 (1.10-1.26) for PICP, Gal-3, and hs-CRP; respectively]; (3) there is a positive interaction between Gal-3 and PICP regarding the association with CV death and allcause mortality whereas no significant interaction is found between PICP and hs-CRP.

The pathophysiology of CV complications is very complex in patients on dialysis, but chronic inflammation certainly plays a major role $[3,27,28]$. Moreover, cardiac and vascular fibrosis are likely to be the main histological pathways involved in the generation of $\mathrm{CV}$ complications related to uremic cardiomyopathy and vascular stiffness [7].

Uremic cardiomyopathy refers to histological modifications of the heart, generated by chronic fluid overload, chronic mineral bone disorder, as well of chronic inflammation, all of them ultimately leading to cardiac fibrosis [4]. Arterial stiffness is associated with an increased mortality in ESRD [29], and it is now well-established that fibrosis 


\begin{tabular}{|c|c|c|c|c|c|c|}
\hline \multirow[b]{2}{*}{ Effect of Gal-3 (per 1SD) } & \multicolumn{3}{|c|}{ CV death } & & \multicolumn{2}{|c|}{ All-cause mortality } \\
\hline & & HR (CI 95\%) & Interaction p-value & & HR (CI 95\%) & Interaction p-value \\
\hline Overall effect & $\longmapsto$ & $1.15(1.06-1.24)$ & & $\longmapsto$ & $1.14(1.08-1.21)$ & \\
\hline Treatment & & & 0.49 & & & 0.70 \\
\hline Placebo & $\longmapsto$ & $1.18(1.06-1.32)$ & & $\longmapsto$ & $1.16(1.06-1.26)$ & \\
\hline Rovusastatin & $\longmapsto$ & $1.12(1.00-1.25)$ & & $\longmapsto$ & $1.13(1.04-1.22)$ & \\
\hline Diabetes Mellitus & & & 0.69 & & & 0.69 \\
\hline No & $\longmapsto$ & $1.15(1.05-1.27)$ & & $\longmapsto$ & $1.16(1.09-1.25)$ & \\
\hline Yes & $\longmapsto$ & $1.19(1.04-1.36)$ & & $\longmapsto$ & $1.14(1.02-1.26)$ & \\
\hline CVD history & & & 0.90 & & & 0.62 \\
\hline No & $\longmapsto$ & $1.16(1.05-1.28)$ & & $\longmapsto$ & $1.14(1.06-1.23)$ & \\
\hline Yes & $\longmapsto$ & $1.17(1.03-1.32)$ & & $\longmapsto$ & $1.18(1.07-1.29)$ & \\
\hline CHD history & & & 0.49 & & & 0.077 \\
\hline No & $\longmapsto$ & $1.16(1.07-1.27)$ & & $\longmapsto$ & $1.17(1.10-1.24)$ & \\
\hline Yes & $\longrightarrow$ & $1.08(0.90-1.30)$ & & $\longrightarrow$ & $1.01(0.87-1.17)$ & \\
\hline Age & & & 0.47 & & & 0.73 \\
\hline$\leq$ median & $\longmapsto$ & $1.13(1.00-1.28)$ & & $\longmapsto$ & $1.15(1.05-1.26)$ & \\
\hline$>$ median & $\longmapsto$ & $1.20(1.08-1.32)$ & & $\longmapsto$ & $1.17(1.09-1.26)$ & \\
\hline Albumin & & & 0.74 & & & 0.33 \\
\hline$\leq$ median & $\longmapsto$ & $1.14(1.03-1.26)$ & & $\longmapsto$ & $1.11(1.03-1.20)$ & \\
\hline$>$ median & $\longmapsto$ & $1.18(1.03-1.35)$ & & $\longmapsto$ & $1.18(1.07-1.31)$ & \\
\hline Yrs on RRT & & & 0.78 & & & 0.77 \\
\hline$\leq$ median & $\longmapsto$ & $1.16(1.05-1.29)$ & & $\longmapsto$ & $1.13(1.05-1.23)$ & \\
\hline$>$ median & $\longmapsto$ & $1.14(1.01-1.28)$ & & $\longmapsto$ & $1.15(1.06-1.26)$ & \\
\hline
\end{tabular}

Fig. 2 Association between Gal-3 and cardiovascular death or all-cause mortality in subgroups of patients (non-adjusted analysis). $C V D$ cardiovascular diseases, $C H D$ coronary heart diseases, $\operatorname{Yrs} R R T$ years on renal replacement therapy (dialysis vintage)

also is the main histological finding of this vascular pathology [6].

Outside the field of CKD, PICP has been shown to be raised in $\mathrm{HF}$, hypertensive or ischemic heart disease with or without HF, and arterial stiffness [9, 14]. Moreover, in $\mathrm{HF}$, serum concentrations of PICP are associated with worse prognosis [30-32], but little is known concerning its clinical risk prediction in dialysis.

The catabolism of high molecular weight PICP is mainly hepatic [33]. Thus, PICP does not accumulate as a consequence of impaired kidney function. Moreover, among prevalent dialysis patients, the concentration of PICP unlikely reflects active renal fibrosis, as patients have established ESRD for long periods. Finally, patients with liver cirrhosis were excluded from the AURORA trial [24]. Consequently, we hypothesized in this study that the concentration of PICP may partly reflect cardiac and vascular fibrosis. Indeed, increased PICP concentrations indicate diastolic dysfunction in ESRD patients undergoing chronic dialysis [34].

Gal-3, a 29-35 kDa protein, is a member of the $\beta$-galectin binding lectin family, which is mainly secreted by macrophages, fibroblasts, mast cells and neutrophils [35]. Gal-3 plays a major role in the pathophysiology of HF, as a marker and a mechanism of inflammation potentially leading to fibrosis [36], but little is known about the implication of Gal-3 in the CV complications among patients on dialysis. Gal-3 appears to be related to chronic systemic inflammation $[22,37]$.

Of note, the interplay between Gal-3 and collagen biomarkers has not been evaluated in the setting of dialysis. The association of Gal-3 and CV outcome in patients with chronic kidney disease (CKD) and ESRD, was previously reported in a pooled analysis of the LURIC (Ludwigshafen risk and cardiovascular health) and the 4D (die deutsche diabetes dialyse studie) trial. The authors reported that elevated Gal-3 was significantly associated with $\mathrm{CV}$ death and all-cause mortality among patients with CKD and ESRD [19]. Gal-3 plays a pivotal role in the inflammatory response by binding to the extracellular matrix (ECM) proteins and modulating adhesions of the immune cells, including T cells, neutrophils, monocytes, and mast cells [38, 39]. In preclinical models, the overexpression of Gal-3 in rats enhanced collagen type I synthesis leading to aldosterone-induced vascular inflammation, remodeling, and fibrosis [40]. Vergaro et al. supported the role of Gal-3 in the development of myocardial inflammation and fibrogenesis. In their study, 

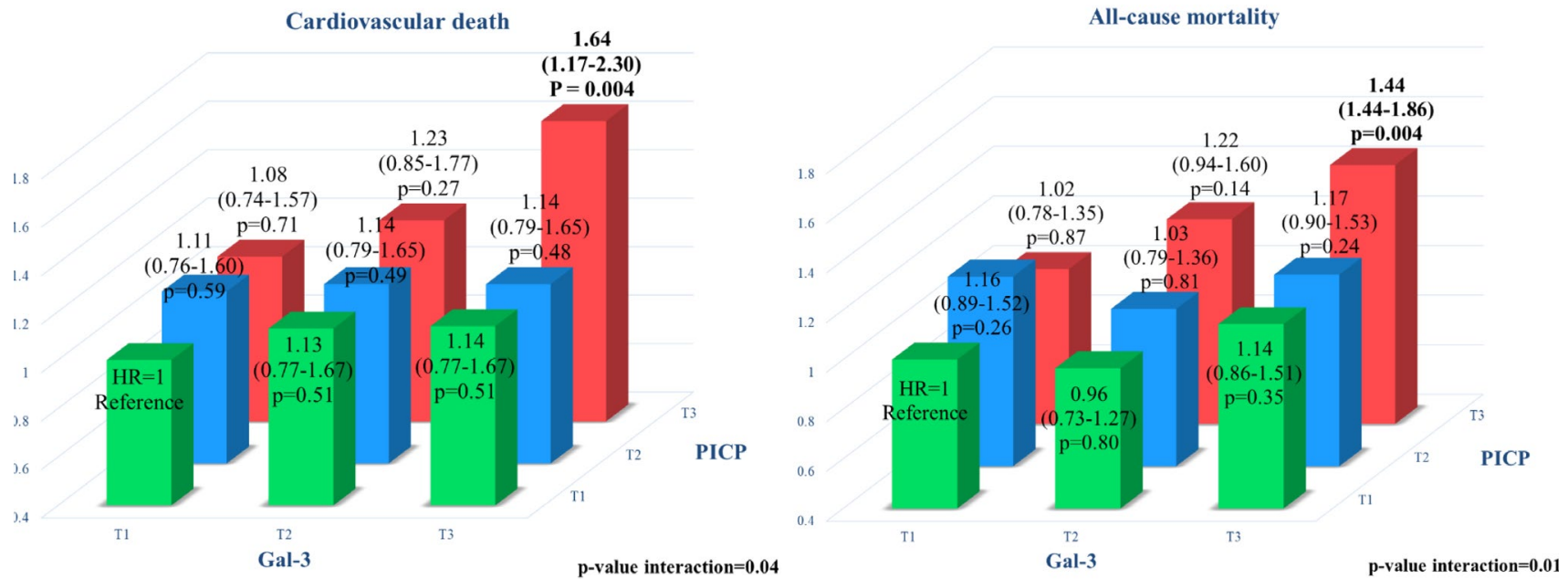

\begin{tabular}{|c|c|c|c|c|}
\hline \multirow{2}{*}{\multicolumn{2}{|c|}{ CV death }} & \multicolumn{3}{|c|}{ PICP } \\
\hline & & \multirow{2}{*}{$\begin{array}{c}\mathrm{T} 1 \\
\mathrm{~N}_{\text {event }} / \mathrm{N}(\%) \\
57 / 245(23)\end{array}$} & \multirow{2}{*}{$\begin{array}{c}\mathrm{T} 2 \\
\mathrm{~N}_{\text {event }} / \mathrm{N}(\%) \\
55 / 221(25)\end{array}$} & \multirow{2}{*}{$\begin{array}{c}\mathrm{T3} \\
\mathrm{N}_{\text {event }} / \mathrm{N}(\%) \\
51 / 206(25)\end{array}$} \\
\hline \multirow{3}{*}{ Gal-3 } & T1 & & & \\
\hline & $\mathrm{T} 2$ & $59 / 234(25)$ & $56 / 215(26)$ & $57 / 215(27)$ \\
\hline & T3 & 48/196 (25) & $56 / 226(25)$ & $83 / 247$ (34) \\
\hline
\end{tabular}

\begin{tabular}{|c|c|c|c|c|}
\hline \multirow{2}{*}{$\begin{array}{c}\text { All-cause } \\
\text { mortality }\end{array}$} & \multicolumn{3}{|c|}{ PICP } \\
\cline { 3 - 5 } & & $N_{\text {event }} / \mathrm{N}(\%)$ & $\mathrm{N}_{\text {event }} / \mathrm{N}(\%)$ & $\mathrm{N}_{\text {event }} / \mathrm{N}(\%)$ \\
\hline \multirow{3}{*}{ Gal-3 } & T1 & $108 / 245(44)$ & $109 / 221(49)$ & $92 / 206(45)$ \\
& T2 & $95 / 234(41)$ & $96 / 215(45)$ & $107 / 215(50)$ \\
& T3 & $91 / 196(46)$ & $108 / 226(48)$ & $137 / 247(56)$ \\
\hline
\end{tabular}

Fig. 3 Interaction between PICP and Gal-3 (in tertiles) for the association with CV death and all-cause mortality

they showed that inhibition of Gal-3 in mice could reverse drug-induced left ventricular dysfunction by reducing myocardial inflammation and fibrosis [41]. Martinez-Martinez et al. reported in a preclinical study that Gal-3 expression is upregulated by cardiotrophin-1 (CT-1) which mediates the proinflammatory and profibrotic myocardial effects [35, 40, 42-45].

In the general population, the mean Gal-3 concentrations fluctuate between 11 and $14 \mathrm{ng} / \mathrm{mL}$ [16, 46-48], whereas they have been reported to be as high as $54 \mathrm{ng} / \mathrm{mL}$ in the 4D patients undergoing hemodialysis [19]. Similar to the latter study, the mean Gal-3 concentration in our study was $69 \mathrm{ng} / \mathrm{mL}$. Moreover, Gal-3 concentrations reach up to $26 \mathrm{ng} / \mathrm{mL}$ in congestive heart failure (CHF) [49-51]. This association between Gal-3 and kidney function may explain the increased oxidative stress partially explaining chronic inflammation. PICP, Gal-3, and hs-CRP concentrations in the current dialysis population were compared to

Table 4 CRP, PICP, and Gal-3 concentrations in the AURORA population in comparison to other populations of high CV risk patients

\begin{tabular}{|c|c|c|c|c|}
\hline Reference & Studied conditions & CRP (mg/L) & PICP (ng/mL) & Gal-3 (ng/mL) \\
\hline $\begin{array}{l}\text { Eschalier et al. [52] } \\
\text { Tarjus et al. [48] }\end{array}$ & Abdominal obesity & $4.0 \pm 6.2$ & $87.0 \pm 52.0$ & $12.2(10.9-15.0)$ \\
\hline $\begin{array}{l}\text { Barasch et al. [53] } \\
\text { Gopal et al. [54] }\end{array}$ & HFrEF & $3.3(1.5-7.7)$ & $406(353-477)$ & $23.0 \pm 12.0$ \\
\hline $\begin{array}{l}\text { Barasch et al. [53] } \\
\text { Gopal et al. [54] }\end{array}$ & HFpEF & $4.1(1.4-9.1)$ & $395(329-503)$ & $22.0 \pm 10.0$ \\
\hline Drechsler et al. [19] & CKD & $6.5(2.5-14.9)$ & N/A & $23.1 \pm 9.9$ \\
\hline $\begin{array}{l}\text { Drechsler et al. [19] } \\
\text { Sawamura et al. [55] }\end{array}$ & Hemodialysis & $10.6 \pm 17.2$ & $162.0 \pm 66.0$ & $54.1 \pm 19.6$ \\
\hline Current study (AURORA) & Hemodialysis & $1.0048 \pm 1.16$ (hs-CRP) & $175.9 \pm 91.2$ & $69.3 \pm 25.1$ \\
\hline
\end{tabular}

$H F r E F$ heart failure with reduced ejection fraction, $H F p E F$ heart failure with preserved ejection fraction, $C K D$ chronic kidney disease, $N / A$ not applicable 
other categories of high CV risk patients [19, 48, 52-55], as presented in Table 4.

Excessive collagen production, fibroblasts and accumulation of ECM are stimulated by the high concentrations of Gal-3 within the myocardium $[14,21,56]$. This explains the significant interaction between PICP and Gal-3 with regard to $\mathrm{CV}$ death and all-cause mortality. The synergistic association of PICP and Gal-3 on mortality, in AURORA study, suggests that in dialysis patients, the process of active fibrosis was driven by Gal-3 overexpression and oxidative stress, more specifically than by chronic inflammation [57]. Indeed, the association between PICP and mortality was found only in dialysis patients without history of $\mathrm{CV}$ disease and coronary heart disease, and, importantly, no interaction was found between PICP and hs-CRP.

Importantly, PICP was more associated with $\mathrm{CV}$ death than morbid events, as there was no significant association between PICP and MACE. In addition, Gal-3 was less associated with MACE than with CV death, further strengthening the relevance of these biomarkers to predict mortality rather than morbidity.

Patients with ESRD suffer from uncontrolled secondary hyperparathyroidism where PICP concentrations may reflect bone degradation [58]. Although this mechanism may account for some of the rise in PICP in our dialysis patients, it is unlikely to be prominent since it would not explain the significant interaction found between Gal-3 and PICP. This interaction may reflect an active process of fibrosis, which is probably more often observed among younger patients in dialysis, without history of coronary heart disease.

\section{Clinical implications}

The combined use of PICP and Gal-3, as a non-invasive assessment of fibrosis, could improve $\mathrm{CV}$ risk prediction on top of validated clinical and biological risk scores in patients undergoing chronic hemodialysis. Hence, the identification of patients with active fibrosis may be a promising approach as they probably have the highest probability to benefit from anti-fibrotic interventions, similarly to what is performed among non-dialyzed patient at risk of heart failure [59]. Yet, the application of this strategy will depend on the prospective validation of a panel of circulating markers in a largescale population, and the stratification of the latter according to their fibrosis' profiles and response to a personalized therapy.

In addition, we tested the hypothesis of possible interaction between rosuvastatin therapy on PICP and Gal-3 concentrations [60, 61], and we did not identify any significant interaction in this post hoc setting. However, this does not necessarily mean that other therapeutic intervention directly targeting fibrosis could not be proposed, based on these biomarkers in the future.
Of note, the anti-fibrotic drug class prototype of the mineralocorticoid receptors antagonists is currently tested in two multicenter randomized study CV prevention studies in hemodialysis achieve (aldosterone blockade for health improvement evaluation in end-stage renal disease trial; NCT03020303), and alchemist (aldosterone antagonist chronic hemodialysis interventional survival trial; NCT01848639) [62].

Our work suggests that Gal-3 may be a key mechanistic pathway underlying fibrosis in dialysis patients, anti-Gal3 therapy for $\mathrm{CV}$ prevention, such as with modified citrus pectin (MCP) may be worth investigating in this setting. As a competitive inhibitor of Gal-3, MCP binds to intracellular and extracellular Gal-3, reduces level of Gal-3 and prevents cardiac fibrosis, inflammation and functional alterations associated in a number of experimental animal models [35, 40, 43].

\section{Limitations}

As in most blood biomarkers studies, it is not possible to firmly validate the fact that the amount of circulating PICP only reflects cardiac and vascular fibrosis. The measurement of parathyroid hormone (PTH) was not carried out among the patients of AURORA study. It would have been insightful in excluding the possibility that high concentrations of PICP were not reflecting bone turnover. We did not adjust our analysis on NT-proBNP, which is an important prognostic factor [63]. In this multicenter prospective randomized trial with more than 2000 patients and adjudicated outcomes, it was not possible to assess other potentially relevant fibrosis biomarkers [8, 64]. Finally, dedicated trials are still needed to test as well as to validate more powerful treatment strategies based on PICP and Gal-3 concentrations.

\section{Conclusion}

Increased concentrations PICP and Gal-3 were synergistically associated with both $\mathrm{CV}$ death and all-cause mortality in patients undergoing chronic hemodialysis. Their significant synergistic interaction with regard to $\mathrm{CV}$ death and allcause mortality may reflect Gal-3 driven active CV fibrosis. The measurement of these biomarkers could be useful in stratifying patients in dialysis according to their $\mathrm{CV}$ risk. The use of these biomarkers to target patients with high probability to benefit from anti-fibrotic, anti-Gal-3 therapy should be further studied.

Supplementary Information The online version contains supplementary material available at https://doi.org/10.1007/s00392-021-01898-9. 
Acknowledgements The authors thank the Biological Resource Center Lorrain BB-0033-00035 of Nancy CHRU for biobank handling.

Funding The AURORA trial was sponsored by Astra-Zeneca. This research is part of IMPROVE-PD project which has received funding from the European Union's Horizon 2020 research and innovation programme under the Marie Skłodowska-Curie grant agreement number 812699. PR, FZ, NG are supported by the RHU Fight-HF, a public grant overseen by the French National Research Agency (ANR) as part of the second "Investissements d'Avenir" program (reference: ANR-15-RHUS-0004), by the French PIA project "Lorraine Université d'Excellence" (reference: ANR-15-IDEX-04-LUE), Contrat de Plan Etat Lorraine IT2MP and FEDER Lorraine. Reagents for galectin-3 were generously provided for free by Abbott $\mathrm{GmbH}$, Wiesbaden, Germany.

\section{Declarations}

Conflict of interest There is no conflict of interests to declare.

Open Access This article is licensed under a Creative Commons Attribution 4.0 International License, which permits use, sharing, adaptation, distribution and reproduction in any medium or format, as long as you give appropriate credit to the original author(s) and the source, provide a link to the Creative Commons licence, and indicate if changes were made. The images or other third party material in this article are included in the article's Creative Commons licence, unless indicated otherwise in a credit line to the material. If material is not included in the article's Creative Commons licence and your intended use is not permitted by statutory regulation or exceeds the permitted use, you will need to obtain permission directly from the copyright holder. To view a copy of this licence, visit http://creativecommons.org/licenses/by/4.0/.

\section{References}

1. Quach K, Lvtvyn L, Baigent C, Bueti J, Garg AX, Hawley C et al (2016) The safety and efficacy of mineralocorticoid receptor antagonists in patients who require dialysis: a systematic review and meta-analysis. Am J Kidney Dis 68:591-598. https://doi.org/ 10.1053/j.ajkd.2016.04.011

2. Chen ZW, Wu CK, Yang YH, Huang JW, Wu VC, Lee JK et al (2019) Efficacy of antiplatelet agent usage for primary and secondary prevention in dialysis patients: a nationwide data survey and propensity analysis. Cardiovasc Drugs Ther 33:471-479. https://doi.org/10.1007/s10557-019-06882-0

3. Kurts C, Panzer U, Anders HJ, Rees AJ (2013) The immune system and kidney disease: basic concepts and clinical implications. Nat Rev Immunol 13:738-753. https://doi.org/10.1038/nri3523

4. Wang X, Shapiro JI (2019) Evolving concepts in the pathogenesis of uraemic cardiomyopathy. Nat Rev Nephrol 15:159-175. https:// doi.org/10.1038/s41581-018-0101-8

5. Chirakarnjanakorn S, Navaneethan SD, Francis GS, Tang WHW (2017) Cardiovascular impact in patients undergoing maintenance hemodialysis: clinical management considerations. Int J Cardiol 232:12-23. https://doi.org/10.1016/j.ijcard.2017.01.015

6. Zanoli L, Lentini P, Briet M, Castellino P, House AA, London GM et al (2019) Arterial stiffness in the heart disease of CKD. J Am Soc Nephrol 30:918-928. https://doi.org/10.1681/asn.20190 20117
7. Zannad F, Rossignol P (2018) Cardiorenal syndrome revisited. Circulation 138:929-944. https://doi.org/10.1161/CIRCULATIO NAHA.117.028814

8. de Boer RA, De Keulenaer G, Bauersachs J, Brutsaert D, Cleland JG, Diez J et al (2019) Towards better definition, quantification and treatment of fibrosis in heart failure. A scientific roadmap by the committee of translational research of the heart failure association (HFA) of the European society of cardiology. Eur J Heart Fail 21:272-285. https://doi.org/10.1002/ejhf.1406

9. Rossignol P, Ferreira JP, Zannad F (2018) Fibrosis mechanistic phenotyping and antifibrotic response determination with biomarkers in heart failure: one single biomarker may not fit all settings. Eur J Heart Fail 20:1300-1302. https://doi.org/10.1002/ejhf. 1214

10. Schiffer E, Liabeuf S, Lacroix C, Temmar M, Renard C, Monsarrat B et al (2011) Markers of vascular disease in plasma from patients with chronic kidney disease identified by proteomic analysis. J Hypertens 29:783-790. https://doi.org/10.1097/HJH.0b013 e3283441129

11. Bai Y, Zhang J, Xu J, Cui L, Zhang H, Zhang S (2015) Alteration of type I collagen in the radial artery of patients with end-stage renal disease. Am J Med Sci 349:292-297. https://doi.org/10. 1097/MAJ.0000000000000408

12. François H, Chatziantoniou C (2018) Renal fibrosis: recent translational aspects. Matrix Biol 68-69:318-332. https://doi.org/10. 1016/j.matbio.2017.12.013

13. Querejeta R, Varo N, López B, Larman M, Artiñano E, Etayo JC et al (2000) Serum carboxy-terminal propeptide of procollagen type I is a marker of myocardial fibrosis in hypertensive. Circulation 101:1729-1735. https://doi.org/10.1161/01.cir.101.14.1729

14. López B, González A, Ravassa S, Beaumont J, Moreno MU, San José $\mathrm{G}$ et al (2015) Circulating biomarkers of myocardial fibrosis. J Am Coll Cardiol 65:2449-2456. https://doi.org/10.1016/j.jacc. 2015.04.026

15. Henderson NC, Mackinnon AC, Farnworth SL, Kipari T, Haslett C, Iredale JP et al (2008) Galectin-3 expression and secretion links macrophages to the promotion of renal fibrosis. Am J Pathol 172:288-298. https://doi.org/10.2353/ajpath.2008.070726

16. O'Seaghdha CM, Hwang SJ, Ho JE, Vasan RS, Levy D, Fox CS (2013) Elevated galectin-3 precedes the development of CKD. J Am Soc Nephrol 24:1470-1477. https://doi.org/10.1681/ASN. 2012090909

17. Yancy CW, Jessup M, Bozkurt B, Butler J, Casey DE, Drazner MH et al (2013) 2013 ACCF/AHA guideline for the management of heart failure: a report of the American College of Cardiology Foundation/American Heart Association task force on practice guidelines. Circulation 128:e240-327. https://doi.org/10.1161/ CIR.0b013e31829e8776

18. Savoj J, Becerra B, Kim JK, Fusaro M, Gallieni M, Lombardo D et al (2019) Utility of cardiac biomarkers in the setting of kidney disease. Nephron 141:227-235. https://doi.org/10.1159/00049 5946

19. Drechsler C, Delgado G, Wanner C, Blouin K, Pilz S, Tomaschitz A et al (2015) Galectin-3, renal function, and clinical outcomes: results from the LURIC and 4D studies. J Am Soc Nephrol 26:2213-2221. https://doi.org/10.1681/ASN.2014010093

20. Obokata $M$, Sunaga $H$, Ishida $H$, Ito $K$, Ogawa $T$, Ando $Y$ et al (2016) Independent and incremental prognostic value of novel cardiac biomarkers in chronic hemodialysis patients. Am Heart J 179:29-41. https://doi.org/10.1016/j.ahj.2016.05.018

21. Hogas S, Schiller A, Voroneanu L, Constantinescu D, Timar R, Cianga $P$ et al (2016) Predictive value for galectin 3 and cardiotrophin 1 in hemodialysis patients. Angiology 67:854-859. https:// doi.org/10.1177/0003319715623397

22. Zhang T, Cao S, Yang H, Li J (2019) Prognostic impact of galectin-3 in chronic kidney disease patients: a systematic review and 
meta-analysis. Int Urol Nephrol 51:1005-1011. https://doi.org/10. 1007/s11255-019-02123-3

23. Holme I, Fellström BC, Jardin AG, Schmieder RE, Zannad F, Holdaas H (2012) Prognostic model for total mortality in patients with haemodialysis from the assessments of survival and cardiovascular events (AURORA) study. J Intern Med 271:463-471. https://doi.org/10.1111/j.1365-2796.2011.02435.x

24. Fellström BC, Jardine AG, Schmieder RE, Holdaas H, Bannister $\mathrm{K}$, Beutler J et al (2009) Rosuvastatin and cardiovascular events in patients undergoing hemodialysis. N Engl J Med 360:1395-1407. https://doi.org/10.1056/NEJMoa0810177

25. Fellström B, Holdaas H, Jardine AG, Rose H, Schmieder R, Wilpshaar W et al (2007) Effect of rosuvastatin on outcomes in chronic haemodialysis patients: baseline data from the AURORA study. Kidney Blood Press Res 30:314-322. https://doi.org/10.1159/ 000106803

26. Fellström B, Zannad F, Schmieder R, Holdaas H, Jardine AG, Rose $\mathrm{H}$ et al (2005) Effect of rosuvastatin on outcomes in chronic haemodialysis patients-design and rationale of the AURORA study. Curr Control Trials Cardiovasc Med. https:// doi.org/10.1186/1468-6708-6-9

27. Schiffrin EL, Lipman ML, Mann JFE (2007) Chronic kidney disease effects on the cardiovascular system. Circulation 116:85-97. https://doi.org/10.1161/CIRCULATIONAHA.106. 678342

28. Cobo G, Lindholm B, Stenvinkel P (2018) Chronic inflammation in end-stage renal disease and dialysis. Nephrol Dial Transplant iii33:35-40. https://doi.org/10.1093/ndt/gfy 175

29. Boutouyrie P, Fliser D, Goldsmith D, Covic A, Wiecek A, Ortiz A et al (2014) Assessment of arterial stiffness for clinical and epidemiological studies: methodological considerations for validation and entry into the European renal and cardiovascular medicine registry. Nephrol Dial Transplant 29:232-239. https://doi.org/10. 1093/ndt/gft309

30. Querejeta R, López B, González A, Sánchez E, Larman M, Martínez Ubago JL et al (2004) Increased collagen type I synthesis in patients with heart failure of hypertensive origin: relation to myocardial fibrosis. Circulation 110:1263-1268. https://doi.org/ 10.1161/01.CIR.0000140973.60992.9A

31. Lijnen PJ, Maharani T, Finahari N, Prihadi JS (2012) Serum collagen markers and heart failure. Cardiovasc Hematol Disord Targets 12:51-55. https://doi.org/10.2174/187152912801823147

32. Löfsjögård J, Kahan T, Díez J, López B, González A, Ravassa S et al (2017) Usefulness of collagen carboxy-terminal propeptide and telopeptide to predict disturbances of long-term mortality in patients $\geq 60$ years with heart failure and reduced ejection fraction. Am J Cardiol 119:2042-2048. https://doi.org/10.1016/j. amjcard.2017.03.036

33. Coen G, Mazzaferro S, Ballanti P, Bonucci E, Bondatti F, Manni $M$ et al (1992) Procollagen type I C-terminal extension peptide in predialysis chronic renal failure. Am J Nephrol 12:247-251. https://doi.org/10.1159/000168453

34. Su CT, Liu YW, Lin JW, Chen SI, Yang CS, Chen JH et al (2012) Increased procollagen type i C-terminal peptide levels indicate diastolic dysfunction in end-stage renal disease patients undergoing maintenance dialysis therapy. J Am Soc Echocardiogr 25:895-901. https://doi.org/10.1016/j.echo.2012.04.025

35. Martínez-Martínez E, Calvier L, Fernández-Celis A, Rousseau E, Jurado-López R, Rossoni LV et al (2015) Galectin-3 blockade inhibits cardiac inflammation and fibrosis in experimental hyperaldosteronism and hypertension. Hypertension 66:767-775. https://doi.org/10.1161/HYPERTENSIONAHA.115.05876

36. Zhong X, Qian X, Chen G, Song X (2019) The role of galectin-3 in heart failure and cardiovascular disease. Clin Exp Pharmacol Physiol 46:197-203. https://doi.org/10.1111/1440-1681.13048
37. Ko W-C, Choy C-S, Lin W-N, Chang S-W, Liou J-C, Tung T-H et al (2018) Galectin-3 interacts with vascular cell adhesion molecule-1 to increase cardiovascular mortality in hemodialysis patients. J Clin Med 7:300. https://doi.org/10.3390/jcm7100300

38. Rabinovich GA, Liu FT, Hirashima M, Anderson A (2007) An emerging role for galectins in tuning the immune response: lessons from experimental models of inflammatory disease, autoimmunity and cancer. Scand J Immunol 66:143-158. https://doi.org/ 10.1111/j.1365-3083.2007.01986.x

39. Jeon S-B, Yoon HJ, Chang CY, Koh HS, Jeon S-H, Park EJ (2010) Galectin-3 exerts cytokine-like regulatory actions through the JAK-STAT pathway. J Immunol 185:7037-7046. https://doi.org/ 10.4049/jimmunol.1000154

40. Calvier L, Miana M, Reboul P, Cachofeiro V, Martinez-martinez E, De BRA et al (2013) Galectin-3 mediates aldosterone-induced vascular fibrosis. Arterioscler Thromb Vasc Biol 33:67-75. https://doi.org/10.1161/ATVBAHA.112.300569

41. Vergaro G, Prud M, Fazal L, Merval R, Passino C, Emdin M et al (2016) Inhibition of galectin-3 pathway prevents isoproterenolinduced left ventricular dysfunction and fibrosis in mice. Hypertension 67:606-612. https://doi.org/10.1161/HYPERTENSI ONAHA.115.06161

42. Martínez-martínez E, Brugnolaro C, Ibarrola J, Ravassa S, Buonafine M, López B et al (2019) CT-1 (cardiotrophin-1)-gal-3 (galectin-3) axis in cardiac fibrosis and inflammation. Hypertension 73:602-611. https://doi.org/10.1161/HYPERTENSIONAHA. 118.11874

43. Calvier L, Martinez-Martinez E, Miana M, Cachofeiro V, Rousseau E, Sádaba JR et al (2015) The impact of galectin-3 inhibition on aldosterone-induced cardiac and renal injuries. JACC Hear Fail 3:59-67. https://doi.org/10.1016/j.jchf.2014.08.002

44. Martinez-martinez E, Calvier L, Rossignol P, Rousseau E, Fernández-Celis A, Jurado-López R et al (2016) Galectin-3 inhibition prevents adipose tissue remodelling in obesity. Int $\mathrm{J}$ Obes 40:1034-1038. https://doi.org/10.1038/ijo.2016.19

45. Martínez-martínez E, López-ándres N, Jurado-lópez R, Rousseau E, Bartolomé MV, Fernández-celis A et al (2015) Galectin-3 participates in cardiovascular remodeling associated with obesity. Hypertension 66:961-969. https://doi.org/10.1161/HYPERTENSI ONAHA.115.06032

46. De BRA, Van VDJ, Gansevoort RT, Kobold ACM, Van GWH, Hillege HL et al (2012) The fibrosis marker galectin-3 and outcome in the general population. J Intern Med 272:55-64. https:// doi.org/10.1111/j.1365-2796.2011.02476.x

47. Ho JE, Liu C, Lyass A, Courchesne P, Levy D (2012) Galectin-3, a marker of cardiac fibrosis, predicts incident heart failure in the community. J Am Coll Cardiol 60:1249-1256. https://doi.org/10. 1016/j.jacc.2012.04.053

48. Tarjus A, Martínez-martínez E, Amador C, Latouche C, El MS, Berger $\mathrm{T}$ et al (2015) Neutrophil gelatinase-associated lipocalin, a novel mineralocorticoid biotarget, mediates vascular profibrotic effects of mineralocorticoids. Hypertension 66:158-166. https:// doi.org/10.1161/HYPERTENSIONAHA.115.05431

49. De Boer RA, Lok DJA, Jaarsma T, Van Der Meer P, Voors AA, Hillege HL et al (2011) Predictive value of plasma galectin-3 levels in heart failure with reduced and preserved ejection fraction. Ann Med 43:60-68. https://doi.org/10.3109/07853890.2010. 538080

50. Lok DJA, Van Der Meer P, De La Porte PWBA, Lipsic E, Van Wijngaarden J, Hillege HL et al (2010) Prognostic value of galectin-3, a novel marker of fibrosis, in patients with chronic heart failure: data from the DEAL-HF study. Clin Res Cardiol 99:323-328. https://doi.org/10.1007/s00392-010-0125-y

51. Tang WHW, Shrestha K, Shao Z, Borowski AG, Troughton RW, Thomas JD et al (2011) Usefulness of plasma galectin-3 levels in systolic heart failure to predict renal insufficiency and survival. 
Am J Cardiol 108:385-390. https://doi.org/10.1016/j.amjcard. 2011.03.056

52. Eschalier R, Rossignol P, Kearney-schwartz A, Adamopoulos C, Karatzidou K, Fay R et al (2014) Features of cardiac remodeling, associated with blood pressure and fibrosis biomarkers, are frequent in subjects with abdominal obesity. Hypertension 63:740 746. https://doi.org/10.1161/HYPERTENSIONAHA.113.02419

53. Barasch E, Gottdiener JS, Aurigemma G, Kitzman DW, Han J, Kop WJ et al (2009) The association between elevated fibrosis markers and heart failure in the elderly: the cardiovascular health study. Circ Heart Fail 2:303-310. https://doi.org/10.1161/CIRCH EARTFAILURE.108.828343.The

54. Gopal DM, Kommineni M, Ayalon N, Koelbl C, Ayalon R, Andreia B et al (2012) Relationship of plasma galectin-3 to renal function in patients with heart failure: effects of clinical status, pathophysiology of heart failure, and presence or absence of heart failure. J Am Heart Assoc 1:e000760. https://doi.org/10.1161/ JAHA.112.000760

55. Sawamura T, Sasagawa I, Kubota Y, Ishigooka M, Nakada T, Adachi M et al (1998) Serum level of carboxyterminal propeptide of type I procollagen in haemodialysis patients. Int Urol Nephrol 30:99-103

56. Lin $\mathrm{YH}$, Chou $\mathrm{CH}, \mathrm{Wu} \mathrm{XM}$, Chang YY, Hung CS, Chen $\mathrm{YH}$ et al (2014) Aldosterone induced galectin-3 secretion in vitro and in vivo: from cells to humans. PLoS ONE 9:1-11. https://doi.org/ 10.1371/journal.pone.0095254

57. Ibarrola J, Sádaba R, Garcia-Peña A, Arrieta V, Martinez-Martinez E, Alvarez V et al (2018) A role for fumarate hydratase in mediating oxidative effects of galectin-3 in human cardiac fibroblasts. Int J Cardiol 258:217-223. https://doi.org/10.1016/j.ijcard. 2017.12.103

58. Bonnin MR, Gonzalez MT, Navarro MA, Griño JM, Cmzado JM, Martinez JM (1996) Evolution of circulating C-terminal propeptide of type I procollagen in patients with chronic renal failure pre and post renal transplantation. Clin Chem Lab Med 34:897-900. https://doi.org/10.1515/cclm.1996.34.11.897

59. Pellicori P, Ferreira JP, Mariottoni B, Brunner-La Rocca HP, Ahmed FZ, Verdonschot J et al (2020) Effects of spironolactone on serum markers of fibrosis in people at high risk of developing heart failure: rationale, design and baseline characteristics of a proof-of-concept, randomised, precision-medicine, prevention trial. The heart omics in aging (HOMAGE). Eur J Heart Fail. https://doi.org/10.1002/ejhf.1716

60. Gullestad L, Ueland T, Kjekshus J, Nymo SH, Hulthe J, Muntendam $P$ et al (2012) Galectin-3 predicts response to statin therapy in the controlled rosuvastatin multinational trial in heart failure (CORONA). Eur Heart J 33:2290-2296. https://doi.org/10.1093/ eurheartj/ehs077

61. Gullestad L, Ueland T, Kjekshus J, Nymo SH, Hulthe J, Muntendam $P$ et al (2012) The predictive value of galectin-3 for mortality and cardiovascular events in the controlled rosuvastatin multinational trial in heart failure (CORONA). Am Heart J 164:878-883. https://doi.org/10.1016/j.ahj.2012.08.021

62. Rossignol P, Frimat L, Zannad F (2019) The safety of mineralocorticoid antagonists in maintenance hemodialysis patients: two steps forward. Kidney Int 95:747-749. https://doi.org/10.1016/j. kint.2018.12.006

63. Untersteller K, Girerd N, Duarte K, Rogacev KS, Seiler-Mussler S, Fliser D et al (2016) NT-proBNP and echocardiographic parameters for prediction of cardiovascular outcomes in patients with CKD stages G2-G4. Clin J Am Soc Nephrol 11:1978-1988. https://doi.org/10.2215/CJN.01660216

64. Tuegel C, Katz R, Alam M, Bhat Z, Bellovich K, de Boer I et al (2018) GDF-15, galectin 3, soluble ST2, and risk of mortality and cardiovascular events in CKD. Am J Kidney Dis 72:519-528. https://doi.org/10.1053/j.ajkd.2018.03.025 